counts from spines of 61 skeletons of the Przewalski horse and he correlates these with counts from four other horses-the domestic horse ( $E$. caballus), mule (E. caballus $\times E$. asinus), donkey (E. asinus), and hemione ( $E$. hemionus). He has found that Przewalski horses are differentiated from other Equidae by having the longest thoracic segment of the spine, the next-tothe-longest lumbar segment, the shortest sacral segment and the next-to-the-smallest number of lateral joints in the lumbar region. Stecher attempts to correlate the spinal characteristics of the five horses with their chromosomal complements. The chromosomal counts of the horses are found in the following descending order: Przewalski horse $2 n=66, E$. przeualskii $\times E$. caballus $2 n=65, E$. caballus $2 n=64, E$. caballus $\times E$. asinus $2 n=63, E$. asinus $2 n=62$, and $E$. hemionus $2 n=54$. Stecher has found that there is a complete correlation between the decreases in chromosome counts and the decrease in presacral vertebrae. There is also a partial correlation with the increase in the anatomical as well as the functional length of the sacrum, additions to the functional length of the sacrum by ankylosis of caudal vertebrae, and the increase of lateral joints in the lumbar region. It may be, therefore, that in the course of equine evolution the chromosome number and the number of presacral vertebrae have decreased, and the numbers of sacral vertebrae and lateral joints have increased.

\section{More Plant Taxonomy}

Some of the latest developments in plant taxonomy were discussed on March 1 when the Experimental Plant Taxonomy Group of the Linnean Society held its tenth annual symposium.

The section Eu-Cochlearia of the genus Cochlearia, scurvy-grass, has always given trouble; Linnaeus described four species and since then there has been considerable taxonomic confusion. Mr J. J. B. Gill of the department of genetics in Liverpool has been investigating cytologically the relationships between thirteen species of Cochlearia. Within these species chromosome numbers of $12,14,25,26,36,42$ and 48 occur, and Mr Gill has found that hybridization between chromosome levels is easy, except when crosses are marle between diploids $(2 n=12$ or $2 n=14)$ and octoploids $(2 n=48)$. Analysis of chromosome pairing in hybrids showed Mr Gill that all the diploid species which he examined are essentially the same; the species with two sets of seven chromosomes have arisen from those species with two sets of six, by aneuploidyone chromosome has been added to the basic number of six. Evidence for this comes from intercrossing these species, when at meiosis the chromosomes show three pairs and one trivalent or six pairs and one univalent.

Mr Gill found that all thirteen species of Cochlearia are related, and that autoploidy has been very important in their evolution. For example, $C$. officinalis $(2 n=24)$ when crossed with a $2 n=12$ species shows between one and six trivalents, and in a cross between two populations of $C$. officinalis, one from Sweden and the other from Italy, there was strong secondary association of bivalents. This clearly suggests that $C$. officinalis developed by autoploidy from a $2 n=12$ species.

Miss Brenda Matfield of the department of botany at Westfield College, London, has been hybridizing species of the sub-series Tormentillae of the genus Potentilla. The species concerned are $P$. reptans $(2 n=28), P$. erecta $(2 n=28)$ and $P$. anglica $(2 n=56)$. The last is thought to be an alltetraploid of the other two-at meiosis it shows only trivalents-but Miss Matfield has so far been unable to synthesize it. Hexaploid natural hybrids are common and three have been given binomials: $P . X$. suberecta $(P$. anglica $\times P$. erecta), $P . X$. italica $(P$. erecta $\times P$. reptans) and $P . X$. mixta ( $P$. anglica $\times P$. reptans). Experimental hybridizations have indicated that $P . X$. mixta may arise in two ways, by hybridization between $P$. anglica and $P$. reptans, or by the fusion of an unreduced gamete of $P$. reptans with a reduced gamete of $P$. erecta. Miss Matfield has shown, by backcrossing $P . X$. suberecta with the parent species, that introgression is theoretically possible from $P$. erecta to $P$. anglica through the hybrid, although this is not known in the field.

Attempts to hybridize $P$. erecta and $P$. reptans were unsuccessful, and Miss Matfield suggests that P.X. italica is not a separate species and that the name is a synonym for $P . X$. mixta-the descriptions for the two are very similar.

Dr M. J. Lawrence, Dr J. S. Gale and Mr A. E. Arthur at the department of genetics in Birmingham have been investigating the causes of genetic diversity in Papaver dubium, the long-headed poppy. The character which they have studied is time of flowering and for the purpose they set up a synthetic natural population in 1964 . In this, natural conditions were simulated as nearly as possible-hand raking and light weeding were carried out in the autumn, but no fertilizer was used. Outbreeding was dismissed as a possible cause of genetic diversity when no overall difference between the mean expression of flowering time was found between crossed and selfed progeny of seven plants sampled from this population. The possibility that genetic variation is a result of environmental heterogeneity of habitat was also discounted when poppies were sampled from a fairly wide climatic range and showed no correlation of climate with flowering time.

The third possible cause of the genetic diversity is selection, and Dr Lawrence and his colleagues have found that this is the operative factor. They found that early flowering poppies seem to be the fittest in that they produce the most viable seed, but populations do not become uniformly early flowering because dormancy is also involved.

Some of these poppies germinate in the autumn and some in the spring, and many of the former are the early flowering types. Thus when the winter is mild and many autumn germinators survive, these will be the fittest, but when the winter is severe there will be more spring germinators, and these, which will in this case produce the most viable seed, will be the fittest. Because the selective advantage fluctuates from one season to another, progress towards the fixation of one genotype with respect to flowering time is retarded and genetic diversity is maintained.

\section{Voltes Face}

\section{from our Molecular Biology Correspondent}

LAST week (Nature, 21\%, 803; 1968) I described three papers dealing with the sub-unit structure of aspartate 